\title{
A novel low temperature synthesis of sodium silicate (water glass) from silica-rich wastes using hydrothermal method
}

\author{
Seun Samuel Owoeye ${ }^{1,}{ }^{*}$, Segun Michael Abegunde ${ }^{2}$ and Babatunde Oji ${ }^{1}$ \\ ${ }^{1}$ Department of Glass and Ceramics, Federal Polytechnic, P.M.B. 5351, Ado-Ekiti, Nigeria. \\ 2 Department of Science Technology, Federal Polytechnic, P.M.B. 5351, Ado-Ekiti, Nigeria.
}

Global Journal of Engineering and Technology Advances, 2021, 06(01), 066-075

Publication history: Received on 01 January 2021; revised on 08 January 2021; accepted on 10 January 2021

Article DOI: https://doi.org/10.30574/gjeta.2021.6.1.0001

\begin{abstract}
This present work aims at synthesizing sodium silicate solutions from selected industrial wastes (waste glass and rice husks) using hydrothermal method. The as-received waste glasses of different mix colors were initially washed, crushed and wet milled for several hours then sieved through $75 \mu \mathrm{m}$ mesh. The sieved recycled glasses were then oven dried at $110 \mathrm{oC}$ for $72 \mathrm{~h}$ to obtain a powdered glass (SLSG). Rice husks were also washed to remove dirt adherence and dried. The dried rice husks were thermally treated in a muffle furnace at $800^{\circ} \mathrm{C}$ for $1 \mathrm{~h}$ then left to cool to obtain whitish rice husk ash (RHA). Both SLSG and RHA were then reacted with $\mathrm{NaOH}$ solution at varying concentration of $3 \mathrm{M}, 4 \mathrm{M}$ and $5 \mathrm{M}$ respectively in a $250 \mathrm{ml}$ Erlenmeyer flask. The mixtures were heated with continuous stirring using a magnetic stirrer at temperatures of $150^{\circ} \mathrm{C}, 170^{\circ} \mathrm{C}$ and $200^{\circ} \mathrm{C}$ respectively for a reaction period of $4 \mathrm{~h}$. Analyses were carried out on the synthesized sodium silicate solutions. The results obtained from the analyses showed sodium silicate synthesized from RHA possessed high viscosity while the $\mathrm{SiO} 2 / \mathrm{Na} 20$ ratio showed they are commercial sodium disilicates which indicates the products are all sodium silicate solutions.
\end{abstract}

Keywords: Sodium silicate; Industrial wastes; Hydrothermal; Viscosity; Chemical composition

\section{Introduction}

Sodium silicate solutions $\left(\mathrm{Na}_{2} \mathrm{SiO}_{3}\right)$ which are commercially referred to as water glass are liquids like dissolved glass containing complex mixtures of anions and polymer silicate particles of silica/sodium oxide $\left(\mathrm{SiO}_{2}: \mathrm{Na}_{2} \mathrm{O}\right) \mathrm{molar} \mathrm{ratio}_{>}$ 2 and possess some water like properties [1]. Sodium silicate is used for broad range of industrial applications such as synthesis of gas adsorbents (silica xerogel) to trap carbon (IV) oxide [2], zeolites and metallic organic framework materials [3], aerogels [4], ingredient in cement production [5]. Other uses of sodium silicate include applications in detergents, corrosion inhibitor, sealants, deffloculants, binders, paper and pulp etc.

Industrially, production of sodium silicate involves fusion of mixtures of sand $\left(\mathrm{SiO}_{2}\right)$ and soda ash $\left(\mathrm{Na}_{2} \mathrm{CO}_{3}\right)$ at elevated temperature above $1200^{\circ} \mathrm{C}$ resulting into formation of glass on cooling; the glass formed is then dissolved in water to produce soluble sodium silicate which is commercially known as water glass [6, 7]. However, this process of synthesizing sodium silicate solutions is considered to be quite costly due to high energy consumption required to attain high temperature and entails negative environmental effects resulting from emission of pollutants such as dust particles, sulfuric oxide, nitrogen and carbon monoxide from decarbonation process. As a result of this, a new and cheaper approach was developed in regard to the chemistry of silica (green chemistry) which involves synthesis in a way that is sustainable, safe, and non-polluting and which consumes minimum amount of materials and energy while less or no waste material is produced. This process involves reaction of silica rich material with aqueous solution of sodium hydroxide $(\mathrm{NaOH})$ in an open system under atmospheric pressure using lower temperature as adopted by

\footnotetext{
* Corresponding author: Seun Samuel Owoeye

Department of Glass and Ceramics, Federal Polytechnic, P.M.B. 5351, Ado-Ekiti, Nigeria.
} 
several works and patents [8 - 12]. In recent times, crucial economic and environmental considerations have geared industries and researchers to develop and improve technologies targeted at drastically minimizing industrial wastes. In this regard, several efforts have been devoted on the utilization of wastes which are known to be highly rich in silica emanating from urban and industrial sectors as alternative to natural silica. In Nigeria, more than 32 million tons of solid wastes are annually produced from various municipal and industrial processes, of which waste glasses and agro wastes account for 70 percent. The usual practice in this country as a developing nation is to primarily treat these wastes in incineration plants and which has raised a lot of environmental concerns. Though waste glasses and rice husks are non-toxic but their accumulations are subject of concern presently in the country. Hence, efforts have now been attached toward recycling and valorization of wastes and by-products in making entirely new and useful products which in turn serve as a means of environmental protection [13]. Recently, several authors have investigated and reported the use of silica rich waste materials as silica source in the synthesis of sodium silicate [7 - 9, 14]. However, these investigations concentrated on agro-waste materials while little work on the use of waste glasses [13,15] utilized single colored waste glasses without varying parameters such as concentration and temperature. Therefore, given consideration to the cost incurred and time of sorting these waste glasses into their different colors, this research adopted the use of mix colored waste container soda-lime-silica glasses through blending of three major colors (green, brown and white). This will not only reduce cost of sorting and beneficiation but also ensure more glasses are recycled within short period.

This present work therefore aimed to synthesize soluble sodium silicate using SLSG (soda-lime-silica glass) and RHA (rice husk ash) as silica sources and sodium hydroxide $(\mathrm{NaOH})$ as soda precursor instead of conventional soda ash $\left(\mathrm{Na}_{2} \mathrm{CO}_{3}\right)$ at different temperatures and concentration of $\mathrm{NaOH}$, then make a comparative study between the sodium silicate obtained from the two silica sources (SLSG and RHA) while chemical composition and ideal physical properties such as viscosity, $\mathrm{PH}$ and specific gravity were investigated.

\section{Material and methods}

\subsection{Materials}

The starting materials used in this work are waste container soda-lime-silica glasses (SLSG) of different colors (green, brown and white), rice husks (RH) and sodium hydroxide pellets (purity 98\%). The SLSG and RH serve as silica sources while sodium hydroxide pellets is used as precursor to sodium oxide $\left(\mathrm{Na}_{2} \mathrm{O}\right)$ instead of soda ash. The sodium hydroxide was purchased from a reliable chemical vendor and used in its as-received state. The SLSG of different colors were sourced from municipal dumpsite while rice husks were obtained as agro wastes from rice milling plant. The as-received SLSG (green, brown and white) were initially washed thoroughly and allowed to dry properly prior to crushing into smaller particle sizes using a laboratory jaw crusher. After crushing, the glasses were then poured with addition of water inside a porcelain-lined ball mill using porcelain balls as milling media; this is to prevent contamination. The milling was done for $48 \mathrm{~h}$ to obtain glass slurries which were later sieved through $75 \mu \mathrm{m}$ mesh. Wet milling was adopted to prevent excessive attrition. The wet-milled recycled glasses were then dried in an electric oven for $72 \mathrm{~h}$ to obtain powdered recycled SLSG. It was possible to blend all the colored glasses together because all container glasses are of similar composition with only variation from the coloring agents in the colored glasses. However, this coloring agents in the colored glasses cannot altered the synthesis of sodium silicate. This practice also eliminates the bottlenecks involved in color sorting thus reducing cost and saving time. For the rice husks, the as-received rice husks were initially washed to remove adhered dirt followed by air drying for $72 \mathrm{~h}$. The dried husks were then stacked inside incinerator for combustion into carbonized rice husk ash. The carbonized rice husk ash was further treated thermally to a temperature of $800^{\circ} \mathrm{C}$ inside a muffle furnace for a holding period of $1 \mathrm{~h}$ at a heating rate of $10^{\circ} \mathrm{C} / \mathrm{min}$ to obtain a pure white rice husk ash (RHA) which was then sieved through $75 \mu \mathrm{m}$ sieve to obtain a fine powder RHA. Both the powdered SLSG and RHA were then characterized following standard procedures. Chemical composition of the SLSG and RHA was examined using high performance Energy Dispersive X-ray Fluorescence (EDXRF) XSUPREME 8000 to quantify the concentrations of $\mathrm{SiO}_{2}$ and other oxides present. Phase identifications were determined by X-ray diffractometer using BRUKER AXS with $\mathrm{D} 8 \mathrm{Advanced}$ diffractometer $\mathrm{Cu} \mathrm{K} \alpha$ radiation XRD in the range of 2 tetha angle from 5 to 80 scanning range. Identification of molecular bonding was evaluated using Fourier-transform infrared spectroscopy (spectrum 100 FT-IR Spectrometer, Perkin Elmer) while the specific surface area of both recycled wastes were determined using Brunauer Emmett - Teller (BET) analyzer. Figures $1(\mathrm{a}-\mathrm{d})$ showed the as -received wastes and recycled wastes respectively. 


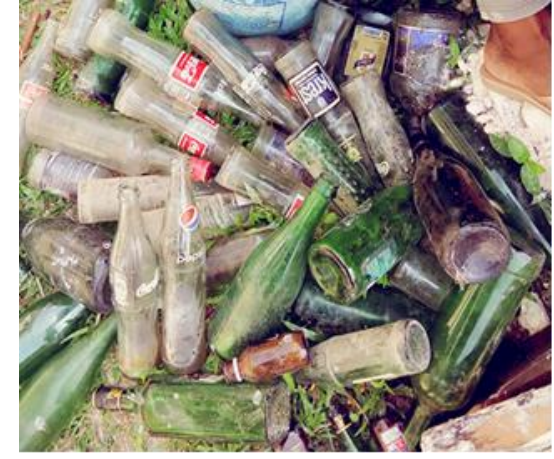

(a)

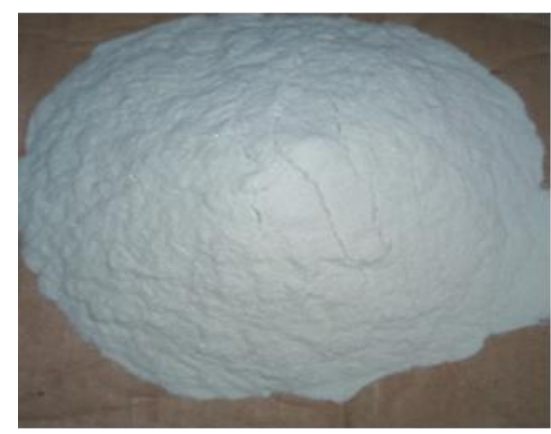

(c)

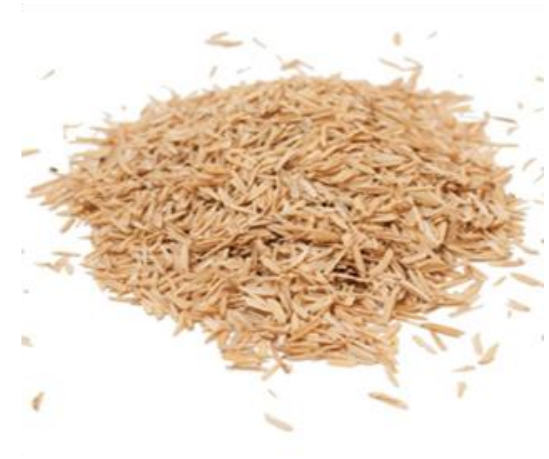

(b)

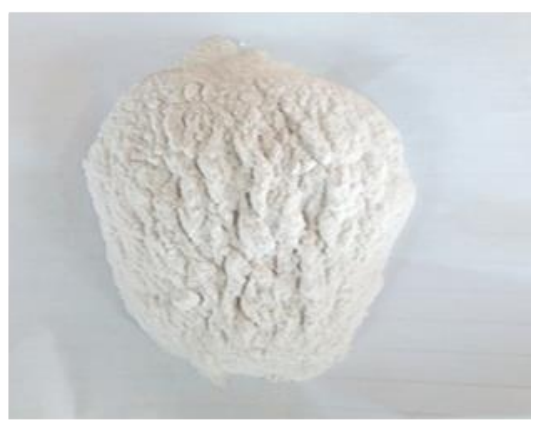

(d)

Figure 1 Representative pictures of (a) waste SLSG (b) RH (c) recycled SLSG (d) RHA

\subsection{Synthesis of sodium silicate (hydrothermal method)}

The hydrothermal method used in this work is an open system following the adopted method of Nittaya and Apinon [16] under atmospheric pressure (14.70 psi). The system consists on the use of glass reaction vessel, heating source, temperature measuring device and a reflux condenser, to ensure constant volume of the reaction mixture. In this work, appropriate amount (10 grams) of recycled SLSG and RHA were at separate time mixed with $80 \mathrm{ml}$ of 3.0, 4.0 and 5.0 M sodium hydroxide solutions respectively in a $250 \mathrm{ml}$ Erlenmeyer flask. The flask containing the mixture was placed on a hot plate connected with a reflux condenser and continuously stirred with the aid of magnetic stirrer at $40 \mathrm{rpm}$ under varying reaction temperature of $150^{\circ} \mathrm{C}, 170^{\circ} \mathrm{C}$ and $200^{\circ} \mathrm{C}$ for a period of $4 \mathrm{~h}$. Constant stirring was ensured to dissolve the silica and produce sodium silicate solutions. The solutions were then filtered using a Whatman No. 41 filter paper to obtain sodium silicate solutions while the residues were washed with $50 \mathrm{ml}$ boiling water.

\subsection{Characterization}

Physiochemical analyses such as chemical analysis, viscosity, $\mathrm{pH}$, specific gravity were investigated to assess the synthesized sodium silicate solutions. The $\mathrm{pH}$ of the synthesized sodium silicate solutions were analyzed using a $\mathrm{pH}$ meter (Oakton pH 700 Benchtop Meter) following standard procedures while viscosity of the sodium silicate solutions were also analyzed with the use of viscometer (Brokfield DV III Programmable Rheometer) at $25^{\circ} \mathrm{C}$.

The chemical analysis of the sodium silicate solutions was carried out to determine the percentage of sodium oxide $\left(\mathrm{Na}_{2} \mathrm{O}\right)$ and silica $\left(\mathrm{SiO}_{2}\right)$ which are two major components of typical sodium silicate present in the synthesized sodium silicate solutions. The $\mathrm{SiO}_{2}$ was characterized using the American Public Health Association (APHA) 4500-SiO 2 C. Molybdosilicate Method [17]. Standard solutions of silica of variable concentrations; 5-25 ppm were prepared from silica stock solution. UV/VIS Spectrometer scan (SpectroLab 753S UV/VIS Spectrometer) of the standards were run and the absorbance measurements at $410 \mathrm{~nm}$ were used to prepare the calibration curve. The prepared samples were diluted to $2.5 \mu \mathrm{l}$ in $50 \mathrm{ml}$ distilled water $\left(2.5 \mathrm{mg}\right.$ in $50 \mathrm{~g}$ solution: dilution factor; $\left.5 \times 10^{-5}\right)$. The diluted solutions of the samples were mixed with ammonium molybdate. The $\mathrm{pH}$ of the resulting mixture was adjusted to 1.2 by adding $1 \mathrm{ml}$ of $1+1$ hydrochloric acid. The mixture was allowed to stand for $10 \mathrm{~min}$ then $2.0 \mathrm{ml}$ of oxalic acid was added. UV-VIS absorbance at wavelength of $410 \mathrm{~nm}$ was taken and the concentration of the sodium silicate was determined. The corresponding concentration of the silicate, in ppm, was determined using the calibration curve. The actual concentration of the silicate, in wt $\%$, was determined using the equation: 
Actual conc. $(w t)=($ conc. $(\mathrm{ppm}) \mathrm{x}$ dilution factor $) /\left(1 \times 10^{-4}\right)$.

$\mathrm{The}_{\mathrm{Na}} \mathrm{O}$ was characterized using Flame Photometer analysis (SpectroLab Flame Photometer SL-160). Firstly, variable concentrations of standard solutions of $\mathrm{Na}_{2} \mathrm{O}$ were prepared; 5-25 ppm from $\mathrm{Na}_{2} \mathrm{O}$ stock solution. The standard solutions were introduced into the flame photometer for inbuilt calibration. The sodium silicate solution was diluted to $2.5 \mu \mathrm{l}$ in $100 \mathrm{ml}$ distilled water $\left(2.5 \mathrm{mg}\right.$ in $100 \mathrm{~g}$ solution: dilution factor; $\left.2.5 \times 10^{-5}\right)$ and introduced into the flame photometer.

\section{Results and discussion}

The chemical compositions of the recycled SLSG and RHA carried out by EDXRF in the form of stable oxides are presented in Table 1. It can be observed that both recycled wastes show similar chemical composition with major component being silica $\left(\mathrm{SiO}_{2}\right)$. However, the highest silica content of $80 \mathrm{wt}$. \% is obtained for RHA while SLSG has 69.4 wt. \% $\mathrm{SiO}_{2}$. The chemical composition of RHA especially the amount of $\mathrm{SiO}_{2}$ is a function of combustion process, temperature, harvest year of rice husks etc. as stated by [18] while that of SLSG varies from one factory to the other. However, the $\mathrm{SiO}_{2}$ content obtained indicates that both wastes have high silica content to be used as silica sources for production of sodium silicate.

Figures $2(a-b)$ indicate the results of the phase constituents of the SLSG and RHA by XRD. It is observed that SLSG showed a single broad band peak between $15^{\circ}-30^{\circ}$ as shown in Figure 5(a) which indicates that SLSG is amorphous [19]. However, in Figure 5(b), the diffractogram of RHA indicates peaks of cristobalite and quartz while tridymite also exist alongside other oxides. The initial broad band peaks observed between $5^{\circ}-20^{\circ}$ in the diffractogram indicate that RHA exhibited slight amorphous nature [19]. However, amorphous silica has been identified to be most soluble form of silica [20 - 21] which is very relevant to the synthesis of sodium silicate for easy dissolution of the silica constituent.

The results of the molecular bonding existing in the SLSG and RHA are presented in Figures 3 (a) and (b) respectively. The IR spectra of the SLSG and RHA were recorded by FTIR at wavenumber ranging from 500 to $4000 \mathrm{~cm}^{-1}$. The FTIR spectra were similar with two predominant transmittance peaks at certain wavenumber in the spectra. The transmittance peaks of RHA were observed at $1069.7 \mathrm{~cm}^{-1}$ and $797.7 \mathrm{~cm}^{-1}$ while the transmittance peaks of SLSG were recorded at $939.3 \mathrm{~cm}^{-1}$ and $767.8 \mathrm{~cm}^{-1}$. However, additional weak peaks were detected for SLSG at $1420 \mathrm{~cm}^{-1}, 2050 \mathrm{~cm}^{-}$ 1 and $2139.5 \mathrm{~cm}^{-1}$ respectively. The predominant intensity peaks at wavenumber range of $900-1100 \mathrm{~cm}^{-1}$ that was observed in both RHA and SLSG might be attributed to Si - O - Si asymmetric bending and stretching vibration bonds indicating the presence of siloxane structural bonding as reported by [22, 23]. This is in similarity with what was observed for synthetic silica reported by [24]. Weak peaks recorded at wavenumber range $700-800 \mathrm{~cm}^{-1}$ in the spectra of both RHA and SLSG can be attributed to stretching of symmetric $\mathrm{Si}-\mathrm{O}$ bond referred to as Silanol as reported by [22]. The additional weak peak observed in SLSG at $1420 \mathrm{~cm}^{-1}$ and wavenumber range $2000-2500 \mathrm{~cm}^{-1}$ might be due to absorption and disturbed silanol respectively.

Table 2 showed the results obtained from the BET analysis respectively. From the data obtained, it is observed that RHA has the highest BET total surface area of $22.3 \mathrm{~m}^{2} / \mathrm{g}$ while SLSG has $1.9 \mathrm{~m}^{2} / \mathrm{g}$. The highest surface area observed for RHA indicates that a large portion of the RHA will react with $\mathrm{NaOH}$ resulting into better dissolution of silica resulting into quality sodium silicate solutions. However, SLSG has the highest micropore area of $1.3 \mathrm{~m}^{2} / \mathrm{g}$.

The results of the $\mathrm{pH}$ measurements of the synthesized sodium silicate solutions from soda-lime glass and rice husk ash are shown in Table 3 and 4 respectively. The results of the $\mathrm{pH}$ measurements showed that the $\mathrm{pH}$ values of the synthesized sodium silicates for both SLSG and RHA increases with alkali $(\mathrm{NaOH})$ concentration of 3M, 4M and 5M used which is actually expected. Also, in relative to synthesizing temperature $\left(150^{\circ} \mathrm{C}, 170^{\circ} \mathrm{C}\right.$ and $\left.200^{\circ} \mathrm{C}\right)$ there is just slight drop in $\mathrm{pH}$ values for RHA synthesized sodium silicate while slight increase in $\mathrm{pH}$ values for SLSG synthesized sodium silicates can be observed. However, there is no typical standard for $\mathrm{pH}$ range of sodium silicate solutions as it is a function of alkali concentration. But, considering the $\mathrm{pH}$ values obtained in this research for both SLSG and RHA synthesized sodium silicate solutions, it can be observed that the $\mathrm{pH}$ values fall within $13.0-14.0$ which is an indication of high alkalinity. In regard to this high alkalinity, the sodium silicate solutions synthesized in this research can be recommended for industrial applications such as soaps/detergent, xerogel, silica extraction and as a clay deflocculant.

The results of the representative viscosity measurement are shown in Table 5. Three best samples were selected for sodium silicate synthesized from SLSG while three best samples were also selected for sodium silicate synthesized from RHA. The selection parameter was based majorly on the visual observation of the products in term of viscousness. From the viscosity measurements, it can be observed that selected samples possessed considerable viscosity though less than 330 Pa.s for commercial sodium silicate [25]. However, it can be observed that sodium silicate solutions synthesized 
from rice husk ash possessed high viscosities above 300 Pa.s falling within the range of commercially produced sodium silicate solution which might be attributed to the high surface area of reaction with $\mathrm{NaOH}$ resulting into better silica dissolution thus enhancing viscosity. However, the viscosities of samples obtained from SLSG are still considerable.

The results of the chemical analysis of the best samples selected are shown in Table 6 . In this work, $\mathrm{SiO}_{2} / \mathrm{Na}_{2} \mathrm{O}$ ratio was also calculated from the results of the chemical analysis obtained to determine the reaction efficiency and to affirm the types of sodium silicate obtained. Based on literature, the type of sodium silicate solutions synthesized is a function of the $\mathrm{SiO}_{2} / \mathrm{Na}_{2} \mathrm{O}$ ratio obtained [26]. It can be observed that the amount of silica $\left(\mathrm{SiO}_{2}\right)$ extracted from the wastes (SLSG and RHA) used as silica sources increased as the synthesized temperature increased from $150^{\circ} \mathrm{C}-200^{\circ} \mathrm{C}$ which indicates that silica dissolution from both SLSG and RHA depend majorly on the temperature. However, the amount of soda ( $\mathrm{Na} 2 \mathrm{O}$ ) dissolved is a function of the concentration of the $\mathrm{NaOH}$ used as source of sodium oxide. It is observed from the $\mathrm{SiO}_{2} / \mathrm{Na}_{2} \mathrm{O}$ ratio that all the best samples selected fall within $1.89-2.45$ and are therefore referred to commercially as sodium disilicate. In term of $\mathrm{SiO}_{2} / \mathrm{Na}_{2} \mathrm{O}$ ratio, samples having high $\mathrm{SiO}_{2} / \mathrm{Na}_{2} \mathrm{O}$ ratio is preferable for industrial synthesis of silica gel as small amount of acid will be required for formation of silica gel [26]. On the average, sodium silicate synthesized from RHA has the highest $\mathrm{SiO}_{2}$ content due to their large surface area exposed for reaction.

Table 1 Chemical composition of the RHAs and WSLSG by EDXRF

\begin{tabular}{|l|l|l|l|l|l|l|l|l|l|l|l|}
\hline & SiO2 & Al203 & CaO & Mg0 & Na20 & K20 & P205 & Fe203 & Cr203 & Mn203 & Ti02 \\
\hline RHA & 80.0 & 1.48 & 1.69 & 3.12 & 0.08 & 2.58 & 9.49 & 1.09 & 0.00 & 0.14 & 0.09 \\
\hline SLSG & 69.4 & 5.03 & 15.03 & 0.55 & 7.22 & 0.65 & 0.09 & 0.71 & 0.13 & 0.02 & 0.65 \\
\hline
\end{tabular}

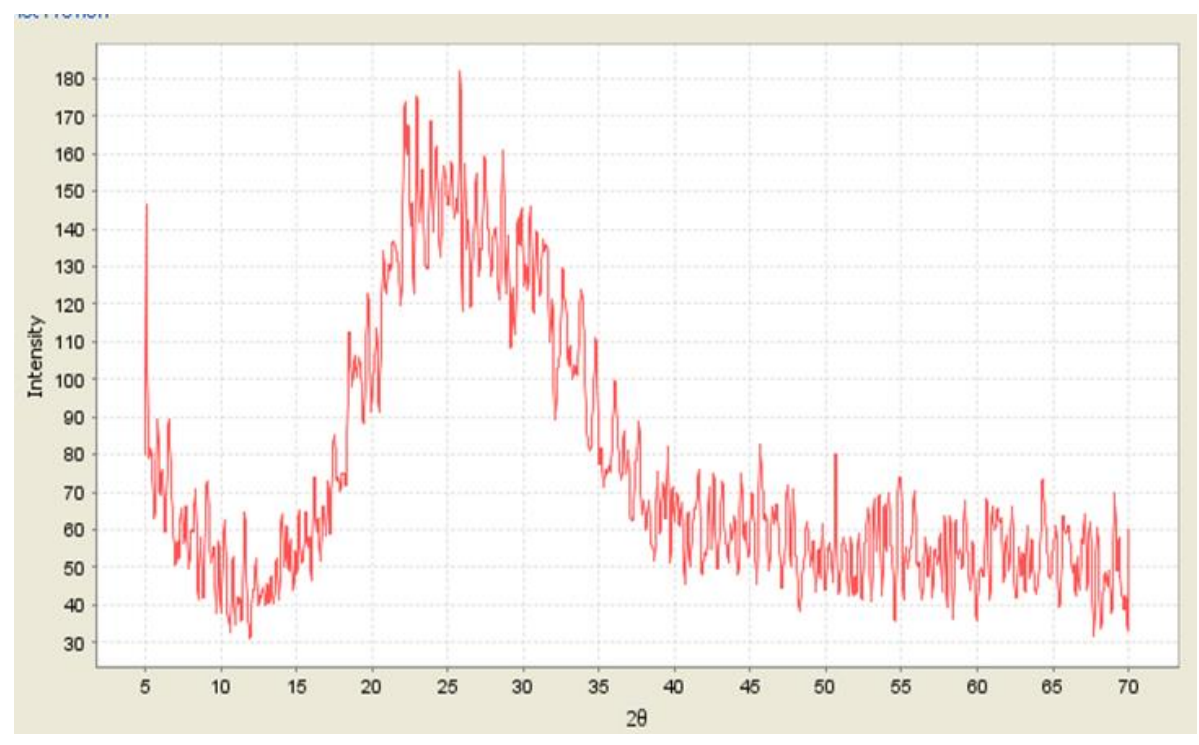

(a) 


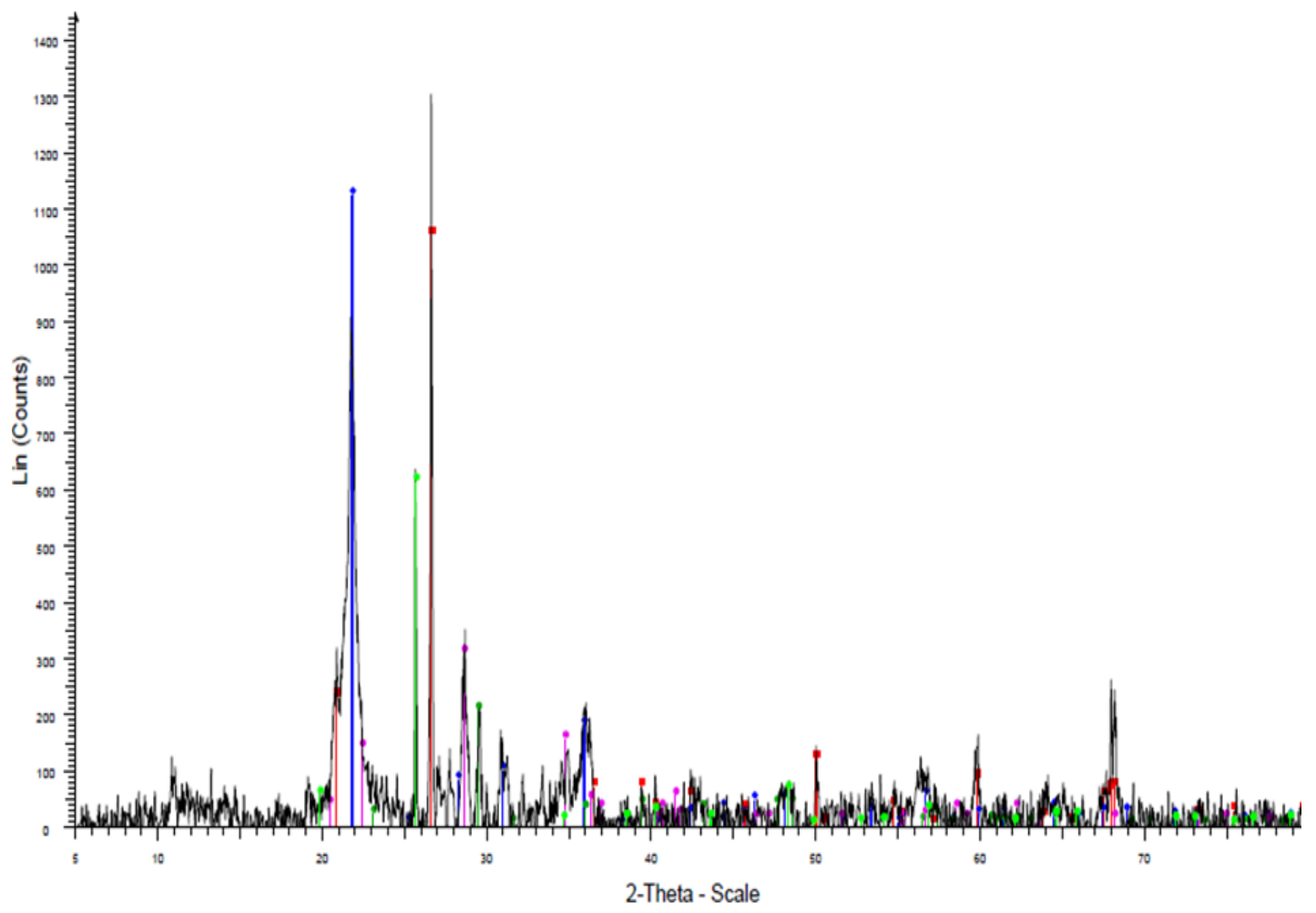

(b)

Figure 2 X-ray diffraction pattern of (a) SLSG (b) RHA

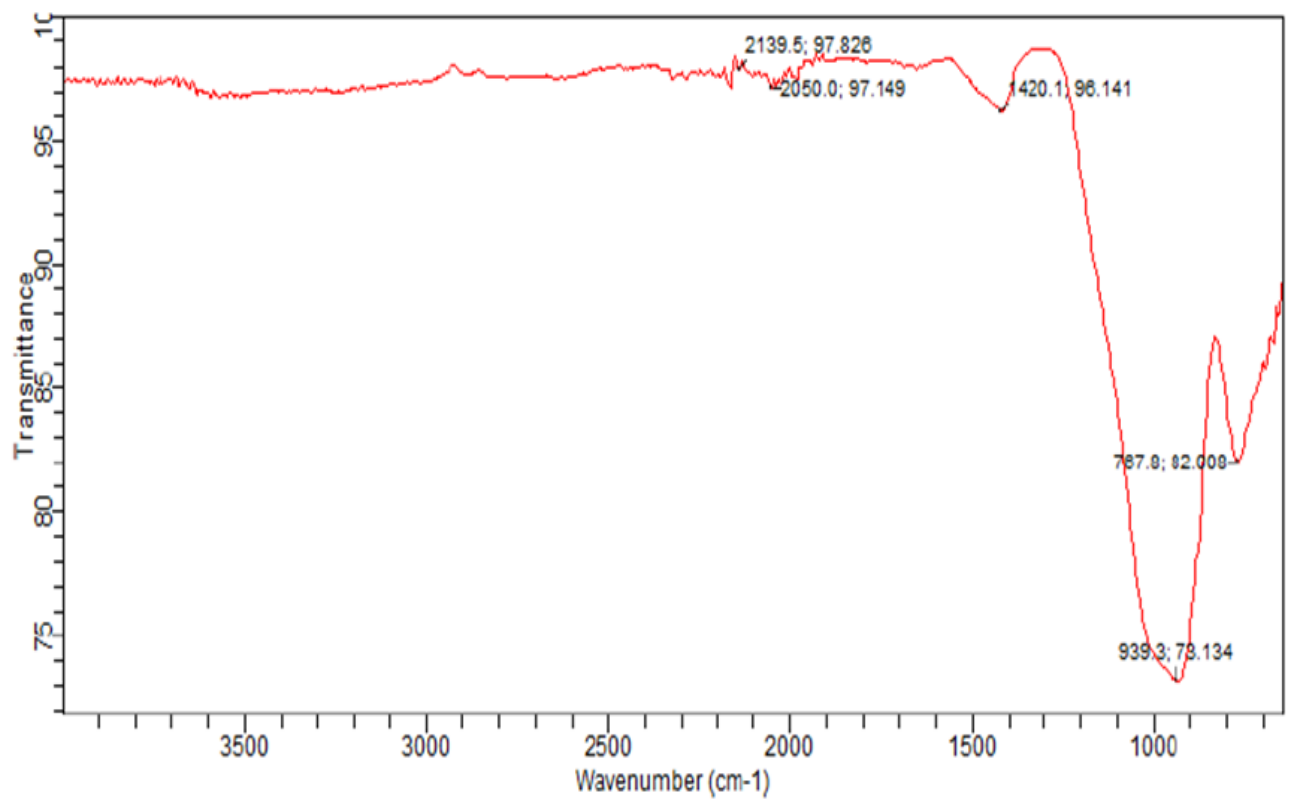

(a) 


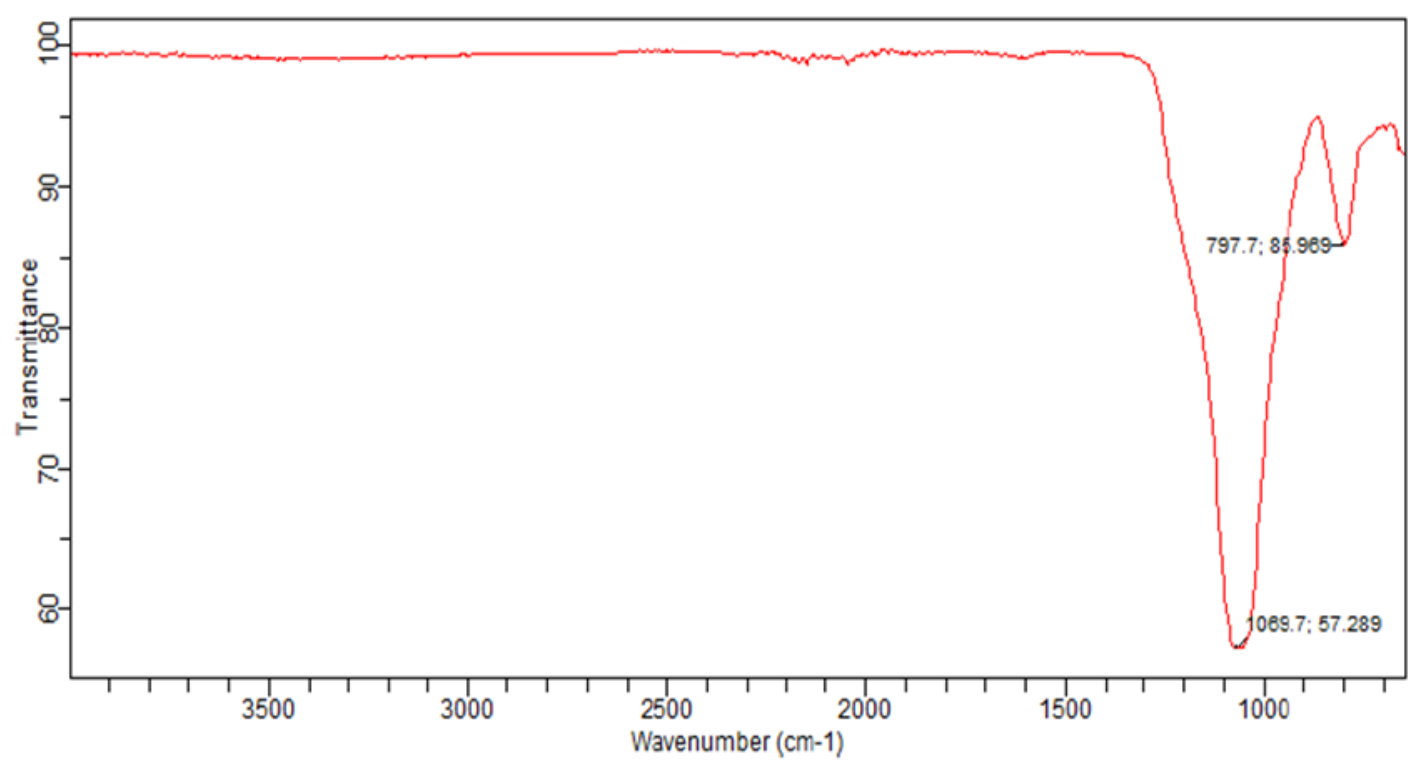

(b)

Figure 3 FTIR spectra of (a) SLSG (b) RHA

Table 2 BET results of the SLSG and RHA

\begin{tabular}{|l|l|l|}
\hline BET parameters & SLSG & RHA \\
\hline BET Total surface area $\left(\mathrm{m}^{2} / \mathrm{g}\right)$ & 1.9 & 22.3 \\
\hline t-Plot micropore area $\left(\mathrm{m}^{2} / \mathrm{g}\right)$ & 1.3 & 0.2 \\
\hline External surface area $\left(\mathrm{m}^{2} / \mathrm{g}\right)$ & 0.60 & 22.2 \\
\hline t-Plot micropore volume $\left(\mathrm{cm}^{3} / \mathrm{g}\right)$ & 0.0007 & 0.0002 \\
\hline
\end{tabular}

Table $3 \mathrm{pH}$ values for sodium silicate solution synthesized from soda-lime glass (SLSG)

\begin{tabular}{|l|l|l|l|}
\hline NaOH Conc. & $\mathbf{1 5 0}^{\circ} \mathbf{C}$ & $\mathbf{1 7 0}^{\circ} \mathbf{C}$ & $\mathbf{2 0 0}^{\circ} \mathbf{C}$ \\
\hline $3 \mathrm{M}$ & 13.55 & 13.68 & 13.69 \\
\hline $4 \mathrm{M}$ & 13.66 & 13.75 & 13.71 \\
\hline $5 \mathrm{M}$ & 13.76 & 13.82 & 14.11 \\
\hline
\end{tabular}

Table $4 \mathrm{pH}$ values for sodium silicate solution synthesized from rice husk ash (RHA)

\begin{tabular}{|l|l|l|l|}
\hline NaOH Conc. & $\mathbf{1 5 0}^{\circ} \mathbf{C}$ & $\mathbf{1 7 0}^{\circ} \mathbf{C}$ & $\mathbf{2 0 0}^{\circ} \mathbf{C}$ \\
\hline $3 \mathrm{M}$ & 13.64 & 13.59 & 13.58 \\
\hline $4 \mathrm{M}$ & 13.82 & 13.84 & 13.77 \\
\hline $5 \mathrm{M}$ & 14.13 & 14.10 & 13.84 \\
\hline
\end{tabular}


Table 5 Viscosity values of the synthesized sodium silicate

\begin{tabular}{|l|l|l|l|}
\hline Silica source & NaOH Conc. & Synthesis Temp. $\left({ }^{\circ} \mathbf{C}\right)$ & Viscosity at $\mathbf{2 5}^{\circ} \mathbf{C}$ ( Pa.s) \\
\hline \multirow{4}{*}{ SLSG } & $3 \mathrm{M}$ & 170 & 232 \\
\cline { 2 - 4 } & $4 \mathrm{M}$ & 200 & 235 \\
\cline { 2 - 4 } & $5 \mathrm{M}$ & 150 & 234 \\
\hline \multirow{3}{*}{ RHA } & $3 \mathrm{M}$ & 150 & 314 \\
\cline { 2 - 4 } & $4 \mathrm{M}$ & 200 & 314 \\
\cline { 2 - 4 } & $5 \mathrm{M}$ & 170 & 305 \\
\hline
\end{tabular}

Table 6 Chemical composition of the synthesized sodium silicate and their SiO2/Na2O ratio

\begin{tabular}{|l|l|l|l|l|l|l|l|}
\hline $\begin{array}{l}\text { Silica } \\
\text { source }\end{array}$ & $\begin{array}{l}\mathrm{NaOH} \\
\text { Conc. }\end{array}$ & $\begin{array}{l}\text { Synthesis Temp } \\
\left({ }^{\circ} \mathrm{C}\right)\end{array}$ & $\begin{array}{l}\mathrm{SiO}_{2} \\
(\%)\end{array}$ & $\begin{array}{l}\mathrm{Na}_{2} \mathrm{O} \\
(\%)\end{array}$ & $\begin{array}{l}\mathrm{H}_{2} \mathrm{O} \\
(\%)\end{array}$ & $\mathrm{SiO}_{2} / \mathrm{Na}_{2} \mathrm{O}$ & Product Name \\
\hline \multirow{3}{*}{ SLSG } & $3 \mathrm{M}$ & 170 & 30.83 & 16.26 & 52.9 & 1.89 & Sodium disilicate \\
\cline { 2 - 7 } & $4 \mathrm{M}$ & 200 & 40.98 & 18.05 & 40.9 & 2.27 & Sodium disilicate \\
\cline { 2 - 7 } & $5 \mathrm{M}$ & 150 & 30.16 & 14.38 & 55.5 & 2.09 & Sodium disilicate \\
\hline \multirow{3}{*}{ RHA } & $3 \mathrm{M}$ & 150 & 28.64 & 12.32 & 59.0 & 2.32 & Sodium disilicate \\
\cline { 2 - 7 } & $4 \mathrm{M}$ & 200 & 42.25 & 17.23 & 40.5 & 2.45 & Sodium disilicate \\
\cline { 2 - 7 } & $5 \mathrm{M}$ & 170 & 36.97 & 18.44 & 44.6 & 2.00 & Sodium disilicate \\
\hline
\end{tabular}

\section{Conclusion}

In this research, synthesis and characterization of sodium silicate solutions (water glass) from valorization of industrial wastes as silica source using hydrothermal method was investigated. Preliminary characterization of the selected wastes was conducted prior to their actual use as silica source in the synthesis of soluble sodium silicate solutions while physio-chemical analysis of the sodium silicate was also carried out.

The results showed that:

- $\quad$ Both rice husk ashes (RHA) and waste soda-lime glass (SLSG) consist of silica content which are high enough to justify their use as silica source in synthesis of sodium silicate as shown by the EDXRF

- The XRD results showed that both RHA and SLSG displayed amorphous silica broad peaks typical of amorphous silica band and which are known to be soluble as supported by literature; making them valuable source of silica for sodium silicate production.

- The FTIR results showed that both RHA and SLSG possessed typical Si - O - Si bonding and which justify their use as silica source in sodium silicate production.

- $\quad$ The Brunauer - Emmett - Teller (BET) analysis showed that RHA possessed high specific surface than SLSG which account for better reaction with $\mathrm{NaOH}$ resulting into more dissolution of silica in the waste unlike SLSG.

- Both temperature of synthesis and concentration (molarity) of $\mathrm{NaOH}$ contributed to the amount of $\mathrm{SiO}_{2}$ dissolution into the obtained sodium silicate and $\mathrm{Na}_{2} \mathrm{O}$ present. However, both the $\mathrm{SiO}_{2}$ and $\mathrm{Na}_{2} \mathrm{O}$ content and the $\mathrm{SiO}_{2} / \mathrm{Na}_{2} \mathrm{O}$ ratio satisfy most commercial grade sodium silicate solutions range of $1.6-3.3$.

- The type of sodium silicate solutions obtained in this work is commercially known as sodium disilicate.

- Based on the results obtained it is therefore concluded that it is feasible to synthesize sodium silicate using waste soda-lime glass and rice husk as silica source instead of constituting environmental nuisance. 


\section{Compliance with ethical standards}

\section{Acknowledgments}

The authors acknowledge the effort of TET fund Nigeria and Centre for Research, Innovation and Development of the Federal Polytechnic, Ado-Ekiti, Nigeria for the research grant given to finance this work.

\section{Disclosure of conflict of interest}

The authors declare no conflict of interest.

\section{References}

[1] Bass JL, Turner GL. Anion distributions in sodium silicate solutions. Characterization by 29SI NMR and infrared spectroscopies, and vapor phase osmometry. J. Phys. Chem. B. 1997; 101: 10638 - 10644.

[2] Witoon T, Tatan N, Rattanavichian P, Chareonpanich M. Preparation of silica xerogel with high silanol content from sodium silicate and its application as CO2 adsorbent. Ceram. Int. 2011; 2297-2303.

[3] Yoo BU, Han MH, Nersisyan HH, Yoon JH, Lee KJ, Lee JH. Self-templated synthesis of hollow Silica microspheres using Na2SiO3 Precursor. Microporous and Mesoporous Materials. 2014; 139 - 145.

[4] Bangi UB, Jung HI Park C, Baek S, Park H. Optically transparent silica aerogels based on sodium silicate by a twostep sol-gel process and ambient pressure drying. Solid State Sciences. 2013; 50 - 57.

[5] Ravikumar D, Neithalath N. Reaction kinetics in sodium silicate powder and liquid activated slag binders evaluated using isothermal calorimetry. Thermochimica Acta. 2012; $32-43$.

[6] Novotny R, Hoff A, Schuertz J. Process for Hydrothermal Production of Sodium Silicate Solutions, United States Patent, $\mathrm{n}^{\circ}$ 5,000. 1991; 933.

[7] Edson LF, Ederson G, Leonard HO, Sergio LJ. Conversion of rice hull ash into soluble sodium silicate. Material Res. 2006; $335-338$.

[8] Maria de Sousa A, Leila V, Claudia M, Cristina F. Silica Sol obtained from rice husk ash. Chemistry and Chemical Technol. 2009; $321-326$.

[9] Owoeye SS, Isinkaye OE. Effects of extraction temperature and time on the physical properties of soluble sodium silicate from rice husk ash. Sci. J. Chem. 2017; 8 - 11.

[10] Deabridges J. Processing for the manufacture of sodium silicate. United States Patent US 4,336. 1982.

[11] Christophliemk P, Novotny R, J von. Laufenberg, Hydrothermal production of clear sodium silicate solutions. United States Patent US 4,770. 1988.

[12] Schimmel G, Kotzian M, Panter H, Tapper A. Process for producing amorphous sodium silicate. United States Patent US 5,229. 1993.

[13] Keawthun M, Krachodnok S, Chaisena A. Conversion of waste glasses into sodium silicate solutions. Int. J. Chem. Sci. 2014; 83 - 91.

[14] Andreola F, Barbieri L, Lancellotti I. The Environmental friendly route to obtain sodium silicate solution from rice husk ash: A comparative study with commercial silicates deflocculating agents. Waste Biomass Valor. 2019.

[15] Torres-Carrasco M, Palomo JG, Puertas F. Sodium silicate solutions from dissolution of glass wastes, Statistical analysis. Materiales de Constr. 2014; 1 - 14.

[16] Nittaya T, Apinon N. Synthesis and characterization of nanosilica from rice husk ash prepared by precipitation method. CMU. J. Nat. Sci. Special Issue on Nanotechnology. 2008; 59 - 64.

[17] American Public Health Association: APHA. Standard methods for the examination of water and wastewater. Published by the American Water Works Association, Water Environment Federation. USA. 1996.

[18] Della V, Kühn I, Hotza D. Rice husk ash as an alternate source for active silica production. Mater. Lett. $2002 ; 818$ -821 . 
[19] Fernandes LJ, Sanchez FAL, Jurado JR, Kieling AG, Rocha TLAC, Moraes CAM, Sousa. VC. Physical, chemical and electrical characterization of thermally treated rice husk ash and its potential application as ceramic raw material. Advanced Powder Technol. 2017; 1228 - 1236.

[20] Ana MS, Leila V, Claudia M, Cristina F. Silica sol obtained from rice husk ash. Chemistry and Chem. Tech. 2009; $321-326$.

[21] Kouassi SS, Andji J, Bonnet JP, Rossignol S. Dissolution of waste glasses in high alkaline solutions. Ceram. Silik. $2010 ; 235-240$.

[22] Sankar S, Sharma SK, Kaur N, Lee B, Young Kim D, Lee S, Jung H. Bio-generated silica nanoparticles synthesized from sticky, red, and brown rice husk ashes by chemical method. Ceram. Int. 2015; 4875 - 48885.

[23] Sarangi M, Nayak P, Tiwari TN. Effects of temperature on nano-crystalline silica and carbon composites obtained from rice husk ash. Composites Part B: Engr. 2011; 1994 - 1998.

[24] Azmi MA, Ismail NAA, Rizamarhaiza M, Hasif WM, Taib H. Characterization of silica derived from rice husk decomposition at different temperatures. AIP Conf. Proc. 2016; 020005 - 1 - 020005 - 7.

[25] Al-maamori MH, Ahmed JK, Ali HM. Production of nano-silica from water glass. Academic Research Int. 2015; 89 $-97$.

[26] Supitcha Rungrodnimitchai, Phokhanusai W, Sungkhaho N. Preparation of silica gel from rice husk ash using microwave heating, J. of Metals, Materials and Minerals. 2017; 45 - 50. 